\title{
Music-making and forced migrants' affective practices of diasporic belonging
}

\author{
Q1 Nicola De Martini Ugolotti (iD) ${ }^{a, b}$

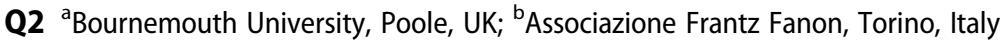

\section{ABSTRACT}

Amid the normalisation of xenophobic narratives surrounding migration, and an overarching 'hostile environment' regulating asylum in Britain, this paper explores music-making as a unique lens to highlight the negotiation of belonging, uncertainty and marginality amongst a group of fifty forced migrants in Bristol. Through a focus addressing the nexus between power, affect and the everyday, this paper discusses how the dehumanising processes that characterise the British asylum regime operate in and through the spaces, bodies and objects constituting its 'ordinary' materiality. Concurrently, this paper addresses how the entanglement of bodies, 'things' and sounds emerging from the co-creation of weekly music groups enabled the group participants to negotiate pleasure, expression and sociality in a context of enforced marginality and uncertainty. Consequently, this paper discusses the music-making sessions as affective practices of diasporic belonging: relationalities arising from multiple forms of displacement that enabled momentary, but productive domains of sociability, co-presence and solidarity beyond ethnic, national, gendered and religious lines. The conclusions consider the contributions of theoretical approaches enabling researchers (and potentially advocates and community organisers) to recognise the stakes and significance of forced migrants (in)visible forms of sociality that take place beside the discursive and institutional frames of State and humanitarian interventions.

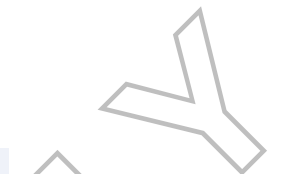

ARTICLE HISTORY

Received 17 January 2020

Accepted 25 June 2020

\section{KEYWORDS}

Music; forced migration;

affect; materiality; diaspora

\section{Introduction}

Despite Britain's claims and international responsibilities as a provider of safe haven for people seeking sanctuary on its shores, in the last three decades the country's approach to asylum has largely been one of increasing experimentation with various means of detention, dispersal and, above all, deterrence (Darling 2011a; Mayblin 2017). This ongoing process has further accelerated since 2012 through an overarching policy framework aiming to create a 'hostile environment' towards migrants and people seeking sanctuary in Britain. Under the auspices of this government agenda, the Home Office enforced a variety of initiatives aiming to curtail asylum seekers' rights and access to public resources (Mayblin and James 2019; Canning 2019; Wilcock 2019). These initiatives co-exist with, and inherently sanction growing public representations portraying forced migrants as 
alien bodies in British society. Despite increasing institutional and public hostility towards refugees, various strands of civil society have nevertheless mobilised through a variety of means ranging from political campaigning to the promotion of a 'culture of hospitality'

Q4 towards people seeking asylum on British shores (Squire 2011; Darling 2013). The latter civic mobilisations (e.g. the City of Sanctuary movement) currently represent key assets in the increasingly underfunded British landscape of asylum (Mayblin and James 2019). However, researchers have also highlighted the ambiguities of considering hospitality as the way to respond to asylum, and contended that sanctuary movements risk the reiteration of problematic normative assumptions towards the issue. Authors have observed that practices of care and generosity in sanctuary initiatives might unintentionally reproduce power asymmetries between volunteers and the beneficiaries of such gestures, thus reinforcing visions of refugees as passive objects of moral compassion (Darling 2011b). Others have highlighted how the promotion of a 'culture of hospitality' often intersects and converges with sovereign powers of distinction and classification, such as implicit divisions between 'deserving' and 'undeserving' categories of migrants (Squire 2009; Darling 2013). These perspectives have highlighted how discourses and practices of sanctuary and hospitality occupy a conflicted position within the politics and moral representations of asylum (Wilcock 2019). Recent contributions have thus argued for the significance of combining the analysis of State policies and civic mobilisations with a deeper engagement with refugees' lived experiences and negotiation of both State-led processes (Mountz 2011;

Q5 Mayblin, Wake, and Kazemi 2020) and accounts of hospitality (Darling 2011b, 2014). Crucial to this endeavour is then an engagement with the 'everyday solidarities, connections, and presences' (Darling 2013, 1797) that refugees and their allies enact in often unremarkable ways in contexts of migration and resettlement. Relatedly, a number of authors have focused on humanitarian grass-roots groups' engagement with 'lateral and anti-hierarchical' forms of solidarity (Rozakou 2016, 188) while exploring the political potentialities of mundane encounters with refugees (Pelham and McGee 2018). These analyses have addressed the contradictions and prospects that derive from grassroots groups' 'political production of sociality' (Rozakou 2016, 187), ranging from bottom-up supply distribution centres, make-shift cinema/theatres, health clinics and leisure initiatives in informal refugee camps (E.g. in Lesvos, Calais). Such emerging focus on sociality turned the attention of forced migration debates beyond the established frameworks of

Q6 humanitarian work and organised political action (Sandri 2018). In doing so, these perspectives highlighted the salience of encounters with refugees that can (if partially and temporarily) interrogate and challenge dehumanising discourses and procedures of migration control, and bureaucratised structures of humanitarian interventions (e.g. eligibility criteria). Yet, while relevant, these perspectives have mostly focused on informal refugee camps as their man site of analysis, and rarely discussed refugees' active roles and stakes in co-creating bottom-up 'socialities of solidarity' (Rozakou 2016, 185; for an exception, see Zaman 2019). This paper thus aims to offer a novel empirical and theoretical contribution to this focus of analysis, by addressing the engagement with musicmaking of about fifty forced migrants from different origins, aged 18-55, who cocreated weekly music-sessions in Bristol for 18 months between 2016 and 2018. Following Lewis (2015), in this paper, the terms 'refugee', 'forced migrant', 'people seeking sanctuary/ asylum' will be used inclusively to refer to people at all stages of the asylum process, unless when relevant to draw attention to the differences produced by the maze of the asylum 
system. Drawing on ethnographic data, and engaging with a theoretical focus addressing the nexus between power, practice and affect, this paper will illuminate the relevance (and negotiation) of the affective politics of asylum at stake in the apparent mundanity of the music-group. Informed by this empirical and theoretical vantage point, this study will also expand Avtar Brah's concept of 'diaspora space' (1996) by addressing the intensities and solidarities that emerged from the entanglement of bodies, sounds and instruments in the music group as affective practices of diasporic belonging. Through this conceptual lens, the paper will consider the significance of (in)visible relationalities that forced migrants enact beside the frames of State and humanitarian interventions, and beyond existing analysis of forced migrants' sociality. The paper's discussion will then address the contributions that the domains and framework here explored can provide to researchers (and potentially advocates and community organisers) addressing issues of forced migration and sanctuary.

\section{Music, migration and the affective politics of asylum}

The relationship between music and migration has been the focus of multi-disciplinary research in social sciences. Authors have explored the topic by analysing textual meanings and production (Bailey and Collier 2006; Coplan 2006), the (re)definition of ethnic and

Q7 national identities (Kaya 2002; Lidskog 2016), and forms of political expression (Martiniello and Lafleur 2008; Kasinitz and Martiniello 2019). Amongst migration scholars, these studies have hugely contributed to the recognition of music as an important domain of cultural (re)production and consumption through which boundaries of belonging are constantly appropriated, asserted and redefined. However, by mainly focusing on lyrics and meaning, production and consumption, and musicians' more or less overt political messages, these contributions have addressed music as a predominantly textual and symbolic domain in relation to migration contexts and processes. This has left much to explore on the embodied, material and affective registers of music, and their capacity to reveal the connections between lived migration trajectories, overarching socio-political processes (e.g. migration policies), and daily practices of belonging, exclusion and sociality. As a partial, but relevant exception to these trends, a small number of studies have explored the importance of music and related activities (e.g. dance) in refugees' daily, and often bodily, negotiation of settlement and belonging (Van Aken 2006; Lewis 2010, 2015). Van Aken's research among Palestinian refugees in Jordan has underlined how 'the body and embodied identities in music and dance have become highly political' (Van Aken 2006, 203) in asserting and re-creating contested notions of place, identification and solidarity in exile. The author highlighted how marriage parties' music and dances had become one of the few and central means to define the boundaries of belonging and solidarity for mobile Palestinian refugees opposing attempts to be labelled and disciplined as 'Jordanian farming communities' (Van Aken 2006, 204). Lewis' studies in Britain (2010, 2015) highlighted how dance and music in community-events provided forced migrants ways to negotiate exclusion and marginality, by allowing 'ephemeral opportunities for security and freedom within precarious lives' (Lewis 2015, 43). The author's discussion of music in relation to issues of 'home', 'identity' and 'community' amongst refugees in Britain also reiterated Malkki's (1995) concern with a lack of recognition of hybridity and fluidity in refugee studies (on this, see also Fiddian-Qasmiyeh 2016). Van 
Aken and Lewis' studies provided insightful perspectives that have addressed some of the mentioned gaps in research on music and (forced) migration. However, the authors' focus on specific events such as marriages and community celebrations left unexplored forced migrants' more banal and affective engagements with music in contexts of resettlement. This paper thus addresses outstanding gaps in research about music and (forced) migration. It does so, by discussing the relationship between music-making and the mundane negotiation of pleasure, belonging and sociality that a group of refugees in Bristol enacted against the backdrop of enforced marginality, destitution and uncertainty that characterise Britain's asylum regime (Darling 2011a; Mayblin, Wake, and Kazemi 2020). In advancing this contribution, this paper builds on an inter-disciplinary scholarship that highlighted how the affective intensities and (in)capacities of bodies, and the conditions through which these emerge, are central in the workings of power (Probyn 2000, 2005; Ahmed 2004a, 2004b; Dawney 2013; Anderson 2016). As these contributions have underlined, understanding how we move, and are moved by affective states that are mediated through our socio-cultural and material environments is crucial to make visible the power relations that emerge through deeply embodied feelings such as fear, shame, despair, joy and pleasure. In this sense, the rubric of affect does refer to an emotive domain, but its origins and scope go much beyond that of the self. The domain of the affective thus needs to be studied in ways that are not limited to the interiority of the human being, and to registers that are not only linguistic or symbolic (NavaroYashin 2009). Such understandings of affects are not diametrically opposed to addressing discourse and meaning, but re-frame the primacy of these domains in constituting social life, by highlighting how subjectivities are shaped by and embroiled in the discursive and material realities (e.g. objects, places, bodies, sounds etc.) which surround them (Navaro-

Q8 Yashin 2009; Dawney 2013). The theoretical focus just briefly outlined meaningfully highlights the political relevance of the everyday and its 'ordinary' affects and materialities in constituting, reproducing and negotiating practices, subjectivities, and social boundaries (Probyn 2000, 2005). However, apart from notable exceptions (Darling 2014; Hughes and Forman 2017) such focus has been only marginally employed to address the 165 affective and material working of contemporary regimes of asylum. This paper thus engages with such focus with a two-fold analytical aim. Firstly, the study will illuminate the ordinary materialisation of the 'politics of discomfort' (Darling 2011a) that characterise the British asylum regime, and its deep reaching effects amongst lives lived in the asylum system. Through this lens, this paper explores how the corporeal and affective states of breathlessness, suspension, immobility, shame and despair discussed in relation to forced migrants' experiences of the British asylum regime ${ }^{1}$ are entangled with the places (e.g. Detention centres, police stations, temporary accommodation structures), things (Food Bank parcels, donated clothing, Home Office letters) and bodies (in detention and detaining, caring and cared for, etc.) that materialise this policy apparatus.

Concurrently, the same theoretical lens allows to examine the places, objects and encounters that characterise lives lived in the asylum system as not simply being reducible to the imposition of State authority and humanitarian discourses 'onto' or 'into' them, but as carrying possibilities of different relationalities and affective appropriations (Darling 2014). Through this perspective, this study will thus engage with music-making as $a$ site of articulation. The music-group will be addressed as simultaneously revealing the intimate reach of asylum regimes in shaping forced migrants' bodies and lives, and their 
temporary, but productive interruptions that emerged from the embroilment of sounds, instruments and affective intensities in the weekly sessions. In this way, this paper provides a dual contribution to scholarly analysis on music and (forced) migration, and more widely to perspectives discussing forced migrants' everyday lives, relationalities and negotiations in contemporary Britain.

\section{Background and methodology}

This paper draws on 18 months of ethnographic research conducted between February 2017 and April 2018 in the weekly music groups, and until December 2018 in other activities with the participants (e.g. Home visits, attending social events). The study is part of an ongoing project aiming to explore the relevance of refugees' social and leisure practices (enacted with or without the support of sympathetic individuals and groups) as negotiations of place, belonging and uncertainty in contemporary Britain.

The group addressed in this paper started in Bristol in October 2016, when a number of refugees joined two local musicians to organise informal sessions, with the aim to co-create a social opportunity for people seeking asylum and other urban residents through playing, learning and/or sharing music. Two local community organisations, the Laureen Ayensu Refugee Arts (LARA) Fund, and Co-Resist CIC logistically supported the starting group activities through the provision of musical instruments and occasional venues to meet. From December 2016 to September 2017, the award of a small-grant permitted the LARA Fund to reimburse venue hire, childcare costs and bus tickets expenses for the participants to facilitate refugees' participation to the sessions. ${ }^{2}$ In April 2018, after some months of self-funding (e.g. through the fees of occasional performances) to cover venue costs and bus tickets reimbursements, and the prospective loss of its usual venue, $^{3}$ the group stopped to meet while trying to find further resources to resume its activities. ${ }^{4}$ From January 2017 until April 2018, I attended the music-group as a participant and a researcher, the latter after my presence in this role was discussed and accepted by the group members. The music sessions usually lasted between two and three hours, with informal social moments at the beginning and the end. The music-making process was self-managed by the participants and semi-structured. Generally, a range of songs, rhythms, melodies played and/or created by those in attendance quickly took over a range of musical games proposed by the musicians to 'warm up' the group at the beginning of the sessions. The types of music played varied enormously, ranging from 'Western' pop and hip-hop, Bollywood songs, South American rhythms, 'traditional' songs from the participants' areas of origin and improvised themes. Musical abilities also varied, including several participants with no experience of playing musical instruments. Across the research period, about sixty participants animated the group overall, with each weekly session counting between seven to more than twenty in attendance. A vast majority of the group members, more than fifty overall, were refugees who had been in the UK from weeks and months to twelve years. ${ }^{5}$ Overall, twenty-seven of the participants were women and thirty-three men, aged 18-55 and coming from sixteen countries. ${ }^{6}$

During the research, my average familiarity with playing music and singing proved enormously helpful in making my presence in the group accepted (or at least justified) and in building informal relationships with the participants. Importantly, the ethnographic involvement in the music-group also enabled me to 'think through' my body, 
and engage with the affective registers emerging through collective play, sounds, movement and singing (see Waitt, Ryan, and Farbotko 2014). In doing so, I methodologically considered how my own position as a White, middle-class, European academic in Britain related to the feelings of boredom, hilarity, connection and uneasiness I experienced in the group, and influenced my observations and engagement with the participants. I thus addressed these corporeal and affective experiences and responses in informal conversations and interviews to address the 'more than what [was] said' (Longhurst, Ho, and Johnston 2008, 215) about the music-group-entanglement.

Throughout the research, I kept a diary which documented these visceral engagements, alongside the many informal conversations and exchanges that constituted the music group and other settings in which I met the participants. Alongside this ethnographic writing, this paper draws on the viewpoints provided by eight participants through semi-structured interviews, and on poetry, song lyrics, and drawings shared with the group and me by other members. The conduction of interviews was contemplated only after several months of fieldwork, and only with participants who had expressed their interest in the research and in voicing their experiences of the group. Considering consent as an iterative process (Lewis 2010), such availability was also checked before the actual interview. The interview respondents had been in the UK between one and a half and twelve years. The interviews were conducted at a place chosen by the participants and lasted between one and three hours, at times involving cooking and sharing food as part of the process. The analysis then included the interviews' transcription and coding and the comparison of emerging codes with the ethnographic field-notes. The study's methodological approach was not without limitations, and some considerations are important to make. Interviews were conducted in English, and language fluency may have hindered the flow of communication with some group members. When relevant, I asked participants for clarifications, and I discussed with them the transcripts of the interviews to confirm that these correctly reflected our conversations. Furthermore, this study only engaged with refugees who participated to the music group. Therefore, the ethnographic field-notes and the interviews do not suggest a 'complete' account of forced migrants' realities and relationalities in Bristol, or Britain more widely. Nevertheless, as discussed in the following sections, this methodological vantage point enabled me to engage and consider both the impact of the asylum regime on the everyday of people seeking sanctuary, and the mundane but productive interruptions of such regime. Participants' names and minor details of their accounts have been modified in this paper to protect their privacy and anonymity.

\section{Embodying asylum}

As we were sitting in a circle of chairs someone asked 'what would you like to happen in this group?' Attending the group for the first time, Maryam uttered straightaway 'I would like to laugh' and added, 'as asylum seekers we don't get to laugh (Field-note excerpts, 13th March 2017)

References to embodied and affective states were a constant presence in the conversations that animated the music-group, together with the sounds of more-or-less-harmoniously played musical instruments, singing and casual chatter. As showed in the above excerpt, these comments often compellingly articulated the immediacy of the group 
setting with the everyday stakes and affective registers of lives lived in the asylum system. When some months after her first appearance at the music group I asked Maryam about this exchange, I wondered if she could recall it. Not only Maryam, a young woman from India who had by then received her refugee status, two years after her asylum application, vividly remembered it, but eloquently explained the relevance of laughter (and its impossibility) in her experience as asylum seeker:

Well, asylum seekers cannot really feel allowed to laugh, isn't it? First is the Home Office stress, the way they treat you, they simply don't believe you ... Then the financial stress, you are not allowed to work, so you have to manage your life in that $£ 37$ per week, third is the family, you are missing the family, you are not with them, fourth is immigration, like, people are judging you as some kind of parasite ... people [refugees] have been attacked ... what happened to another could happen to you anytime ... and the waiting ... it's so many things in your life that don't depend on you anymore that you even feel that laughing is not up to you anymore ... so it's like you want to find somewhere where you feel you can have that senseless talk, joke ... so, even if you don't want to laugh, but can't hold to laugh, you can feel alive ... so, when they asked me what I want from this, 'I want to laugh', that's why ... (Maryam, interview, emphasis added)

Maryam's account emblematically expressed how her everyday experiences as an asylum seeker summed up to a cutting sense of loss and longing for an apparently unremarkable feature of everyday life such as laughter. More precisely, in Maryam's account her experiences of obscure and hostile institutional processes, existential suspension and everyday marginality as an asylum seeker became seamlessly embodied in her feeling incapable to laugh. Similar to those of several other participants, Maryam's account echoed academic analysis that illuminated the embodied politics of asylum in contexts of refugees' humanitarian government (Fassin and D'Halluin's 2005; Schmoll 2014). These perspectives addressed forced migrants' bodies as (bio)political sites on which discursive representations of refugees as passive, vulnerable, or 'tricksters' are inscribed by the State and humanitarian actors through a continuum of 'paternalistic humanitarianism, bureaucratic violence, and compassionate repression' (Beneduce 2015, 10).

However, in Maryam and other participants' accounts their body was not just discursively inscribed with representations (and expectations) of victimhood and trauma (e.g. through medical certifications used as evidence for asylum claims, see Fassin and D'Halluin 2005; Beneduce 2015); nor, it represented only a symbol of the bordering practices enacted to manage migration (e.g. fingerprints discussed by Schmoll 2014). Rather, in several of the accounts emerging from the music group, the participants' bodily sensations and (in)capabilities seemed to name 'the feelings that their daily environments inflicted upon them' (Navaro-Yashin 2009, 4). The participants' bodies and affective states manifested how pervasive experiences of suspension, exclusion and immobility relied upon the presence of 'ordinary' places, objects, and encounters that composed their lives in the asylum system. During one of the music groups, Azhari, a middle-aged man from Sudan who usually stood very serious-looking and composed in most of the sessions, joined the up-beat rhythm by hitting hard and loud the bass on a drum while dancing. At the end of the session, he started complaining 'my back is hurting now' while opening in a big smile. Noticing this, I teased him: 'Never seen someone with a backache smiling so much, Azhari'. Still laughing, Azhari landed two big pats on my shoulder and replied: 
My friend, I have been sitting three years on that sofa [in temporary accommodation] ... I would just sit there and wait, three years ... in April it will make one year I have my papers [refugee status], I can go anywhere but my country, but most days I still feel like I cannot even move from that sofa ... all this waiting entered inside my bones ... But today I felt the music ... wallahi [I swear] this pain is not pain, my friend (Field-notes excerpt, 14th April 2017, emphasis added)

The excerpt focusing on Azhari's 'joyful' backache to some extent expanded Maryam's account. Azhari's bodily and affective responses to the percussion rhythms highlighted the weekly music-group as a site where pleasure, pain, (im)mobility, suffering and laughter could literally rub against each other. Furthermore, the excerpt underlined the corporeal and affective intensities emerging from the entanglement of movements, sounds, and things that constituted the music group, as well as other daily encounters and environments. Azhari's bodily and affective states could not be disentangled from the 'sovereign attempts to manage migration' (Darling 2017, 183) enacted by the Home Office through compulsory dispersal policies. His experience of bodily loss of control was deeply entangled with the unchosen and indefinitely temporary living spaces constituting the materiality of his 'policy-imposed liminality' (Hynes 2011) as a dispersed asylum seeker in Bristol. Importantly, as also reported by other participants, the deeply embodied feelings of suspension and immobility that Azhari experienced did not end with the moment he received refugee status. Rather, these feelings 'stuck' with him, despite his determination to build his life in Britain, and the rights now provided by his longawaited legal status; the spaces and objects that materialised his life-on-hold (e.g. the sofa) still seemingly acting as 'objects that do not allow subjects to carry out their will' (Ahmed 2004a, 42). At the same time, Maryam's quest for laughter, and Azhari's 'joyful pain' in re-experiencing the pleasure (and aches) of movement highlighted how affects and bodily capacities are 'not linear effects of power apparatuses' (Anderson 2016, 80). Addressing and seeing unfold the affective states emerging from the music group not only illuminated the materiality of processes through which passivity, powerlessness and uncertainty were inscribed on the participants' bodies. Far from representing only the lived experiences of 'bodies made docile through pain' (Mayblin, Wake, and Kazemi 2020, 14), Maryam and Azhari's affective longings and intensities highlighted how their bodies' (in)capacities were constantly negotiated 'amid the ongoing (re)composition of encounters' (Anderson 2016, 82) that constituted their lives as forced migrants in Britain. In this sense, Azhari, Maryam, and other participants' practices were emblematic of the mundane, contingent but productive encounters that at the same time illuminated and interrupted the affective politics of asylum that kept them 'alive but in a state of injury' (Mbembe 2003, 21; in Mayblin, Wake, and Kazemi 2020, 5). It is to these affective interruptions, and their implications for the participants' negotiation of sociality, belonging and uncertainty that this paper will now turn in the following section.

\section{‘Here to Play’: Interrupting the affective politics of asylum}

It's like a journey, every time the drumming ... especially the drumming is very powerful and bold ... when we hit the drums together and the sound fills the room, the palms gets all warm and red, and you feel the skin [of the drum] shaking under your hands, you know? I like it, it's like a journey every time we'd be drumming, it may be five minutes, but it's like a journey, it starts from somewhere, and you are becoming some other person in the end of the journey, 
you know? Because you forget about it, you arrive here and you forget, you wait and keep wait [ing] ... and you become someone else ... (Shukri, interview)

It's good you know? I like the drumming, the singing ... A chance to release this prisonness ... being stuck where you cannot breathe ... instead even one sound, one melody sometimes is an opportunity for me to breathe, to sing ... (Farah, interview)

In the accounts above, Shukri and Farah, respectively from Iraq and Iran, highlighted the everyday as an affective domain where bodies move and are moved in relation to other human and non-human bodies, things and places in ways that are shaped, but not determined, by power, history and discourse (Navaro-Yashin 2009; Anderson 2016). Relatedly, Dawney's (2013) conceptualisation of the interruption pays attention to the instances in which 'the body moves [and feels] in unexpected ways' (629) as conjunctures that illuminate and interrogate the political, material and affective constitution of 'ordinary' realities and 'modes of experience' (629). For Shukry and Farah, who had been in the UK respectively for five and one year, the affective and embodied intensities surfacing while playing music and singing became contingent, but significant disruptions of the suffocating feelings of 'prisoness' and suspension that constituted their everyday lives in Britain. Significantly, their bodily responses to the music group-entanglement intensely reflected and interrupted the affective politics of asylum; the discursive and material production of refugees' subjectivities enacted through the 'ordinary' materialisation of patterns of fear, hope, despair, uncertainty and (im)mobility amongst forced migrants.

As Shukry and Farah observed, such affective interruptions could not be isolated by the environment and relationalities in which they took place, and in fact emerged in conjunction with them. Instruments and sounds did not represent mere means to actualise specific, or explicit aims planned by the participants, or the group. Nevertheless, instruments, bodies and sounds often unexpectedly, but actively mediated and enabled the relationalities and intensities through which isolation, boredom, and suspension were interrupted to make space for 'forgotten' subject positions and forms of sociality. Following Anderson (2016, 105), bodies, things, sounds and affects seemed to 'carry traces' of each other in the music-group-entanglement, creating a 'heterogeneous collective' (Hughes and Forman 2017) that exceeded the ordinary encounters and affective states characterising the participants' everyday lives. Yet, although 'unexpected' and not following linear paths of intentionality, the affective registers discussed here were traced by the group members as part of personal and collective (hi)stories (see also Navaro-Yashin 2009). Furthermore, the participants often qualified the intensities surfacing from the group as significant, and rare encounters enabling them to negotiate suffocating feelings of isolation, uncertainty, and the ordinary materialisation of 'hierarchies of human worth' (Mayblin 2017) in their lives:

B.: Everything I do here [in Britain] reminds me I am refugee [...] If I look at myself at the mirror I fight to remind myself I am not just refugee, but when I come here [the music group] I don't feel refugee ...

N.: This despite most of the people in the group being refugees?

B.: $\quad$ Yes ... you see, we are all same, refugees, immigrants, people, you know? How can you say who is refugee, who is not, when you singing, or laughing, or the instruments playing? That's why this is good ... we are just people who try to make new home here (Bilal, interview) 
At the time of the interview Bilal, a visual artist in Ethiopia, had been waiting in Bristol for a response to his asylum application for about eighteen months. During our conversation he meticulously listed how every place and activity he attended as an asylum seeker, from the temporary accommodation he lived in, to the supporting agencies where he received free-food, clothing, and legal advice, reminded him of his status in Britain. While grateful for the support received, the daily encounters with(in) the above mentioned spaces also constantly reminded him of the passivity, enforced liminality and suspension of his life. Paraphrasing Mountz $(2011,386)$, in Bilal's experience who he was was daily remarked by the spaces, objects and encounters that, regardless of intentions, contributed to define him as a 'refugee'. Conversely, the group's self-organised structure and lack of any aim beyond making music and socialising stood out in his daily experience as not reproducing any subtle, but powerful differentiation between 'service proyiders' and 'users' that often characterise 'spaces of care' for refugees (Darling 2011b). The overall entanglement of people, (hi)stories and instruments 'trying to make a new home' thus afforded Bilal rare and momentary, but important contexts of sociality that helped him to displace apparently unescapable subject positions such as 'refugee', 'service user' and ultimately 'guest' in Bristol, and Britain. In a similar way, definitions of what could be considered (un)familiar and who could be considered 'us' amongst an heterogeneous group of people with different experiences of displacement and (im)mobility made often space for temporary, though 'sticking', forms of commonality that emerged in and through sounds, bodies and affective registers:

"Rafik and Shukri (with her daughter) arrived early and started to organize the room with us. As more people joined in, some started to play the instruments; Maryam started beating on a drum, few others followed/along (me included), and as the rhythm took momentum Fartun started singing in Arabic, then paused and started another song "I didn't come to the market to buy, but to see you" said one (as Fartun would translate to me later). "You know that Said, don't you?", Fartun teased, as Said nodded and laughed loudly while hinting more words of the song. Moussa was also taken by the rhythm and hit with both commitment and enjoyment thumping bass tones. Farah, Maryam and Shukri kept hinting more songs in Sorani, then Farsi and Arabic, "you came out of the neighbour's house and did not greet me ..." and lead in fact the rest of the group in an impromptu as much as exhilarating improvisation which ended with roaring laughter, red palms and breathless lungs. As I sat by Moussa, he suddenly turned to me and enthusiastically said how all that reminded to him what would happen in Sudan at a wedding or when receiving a visit from afar "What do you think we are celebrating today?" I asked him "That we are seeing again this week" he replied. (Fieldnotes, 27th July 2017)

Ideally joining and extending the data presented so far, in this excerpt the affective and embodied practice of music-making simultaneously enabled relations with lived memories, past and current contexts and imagined futures that (e)merged through the embroilment of instruments, melodies, and other participants' bodies. Discussions that centred on a material analysis of everyday lives have argued for a conceptualisation of mundane bodily and affective practices as participating in the reproduction and negotiation of power regimes that fashion actions, subjectivities and social boundaries (Probyn 2000, 2005). Expanding these perspectives, the data underlined how the affective intensities and relationalities surfacing during the sessions not only contributed to shape forms of sociality within the group, but spilled over its spatial and temporal boundaries, contributing to shape further (in)visible practices of belonging. 
Maryam and Samira often joked how their religious affiliations (Christian and Muslim) and nationalities (Indian and Pakistani) should have given them, as of today, plenty reasons not to be friends: 'but we speak basically the same language, and like the same music' Samira explained during an informal conversation at the end of a performance for Refugee Week in July 2017. After being assigned a council flat few weeks before, Maryam opened it to Samira and other Muslim women in temporary accommodation who lacked a place to cook and break the fast during the upcoming month of Ramadan. Similarly, after the end of the group's activities, Shukri gave continuity to her and other women's efforts to set up women-only music and dancing groups with the support of local charities. Shukri and other participants explicitly mentioned the shared challenges they experienced as women (and often mothers) in the asylum system, and the experiences of 'carelessness', solidarity and belonging that emerged in the group as a reference for their efforts.

These insights thus expanded previous discussions about the role of music in forced migrants' negotiation of belonging and settlement. Existing contributions underlined music-making as an important means to define boundaries of identity in exile, and discussed music events as spaces segmented along language or ethnic lines, where refugees could proudly engage in 'their' culture and relax from constant engagement with the unfamiliar (Van Aken 2006; Lewis 2010, 2015). More mundane than the events observed by these authors (often festivities and weddings), the weekly groups attracted diverse members of Bristol's refugee population who often started attending in an attempt to shake off common realities of isolation, boredom and marginality.

As such, participation in the group varied significantly across the lines of age, gender, origins, religion, and, as discussed, definitions of 'familiar' and 'unknown' often shifted and blurred, with the participants often discovering 'surprising' common passions for (un)familiar songs, instruments and music styles. This is not to argue that the sensory and affective practices of music-making erased forms of national, ethnic or religious identification amongst the participants. The group members kept considering themselves Ethiopian, Kurdish and/or Muslim in and out of the music space. However, in the context of the weekly sessions these categories seemed to lose their centrality to define moments and practices of sociality, echoing Fiddian-Qasmiyeh's (2016) observation that a persistent focus on refugees nationality-based social networks can make invisible refugees' relationalities in contexts of resettlement. Yet, the encounters characterising the group are not to be idealised, and the data discouraged any framing of the weekly sessions as sites of uncomplicated belonging or romanticised resurgence of community across boundaries of difference and status. Notably, some of the participants discussed how the group's setting (e.g. time, and type of venue) restricted opportunities to participate for some members of Bristol refugee population, in particular people with physical disabilities and single-mothers in distant temporary accommodations. These conditions thus unwit490 tingly contributed to re-inscribe the status of some refugees in Bristol as 'excluded exclusions' (Mountz 2011, 393) even from the group's spaces and practices of sociality. Relatedly, the music-sessions did not represent the only encounters enabling refugees and their allies to co-create forms of sociality and belonging in Bristol, or elsewhere. Other groups and initiatives have been striving in various ways to co-create spaces of conviviality, expression and solidarity in this, and other cities in Britain, and beyond (Zaman 2019). Following these considerations and caveats, the data presented so far aimed rather 
to illustrate the significance of addressing refugees' (in)visible relationalities to expand and complicate existing frameworks employed to understand and engage with forced migrants' socialities, solidarities and everyday lives in contexts of resettlement. The next section of this paper will thus consider in more details the contributions this research focus can offer in dialogue with Avtar Brah's notion of diaspora space.

\section{PUscussion:mysic-makina and affective practices of diasporic belonging}

I been thinking for a while

How to put pen to paper.

It doesn't matter how, but,

I should just have to say it.

I am glad you here, very glad!

Because you have helped,

to dispel the fears.

From across the seas and far lands strangers have gathered here.

We have shared laughter, smiles and sometimes tears.

No matter what some think, even when

they want to classified people as them and us.

I am sooo very glad, that you are here.

Helping all to wake up from lethargic lives,

bringing richness and variety, new flavours, possible tastes and even sounds,

that not only your ears but your brain too, will learn to hear.

Words that bursts out in your mouth like fully mature berries, filling you with gladness, like a giggles...

Yes Alhamdulillah's, that you are here.

So we can say together, there is not Them and Us.

There are only Us, here.

(Poem by Yanet, sent to the author as recited to the group on 9th July 2017, emphasis in the text sent)

The affective intensities emerging from the entanglement of bodies, sounds, and instruments that constituted the music group informed this paper's discussion in addressing not (only) what collectively making, sharing and sensing music meant for the participants, but what it did. What emerged from the accounts, field-notes and the participants' creative expressions (as Yanet's poem above) did not highlight music-making only as a cultural and symbolic signifier of ethnic, religious, or national identifications in exile, as generally discussed in the literature on music and (forced) migration. Rather, the sessions' entanglement of bodies, instruments and sounds in the weekly music group contributed to underline music-making as an affective practice of diasporic belonging.

With the concept of affective practices of diasporic belonging, this paper aims to highlight forms of sociality deeply embedded in mundane activities and registers that arise from shared (tough differently experienced) forms of displacement, and that enable 
momentary, but productive domains of belonging beyond ethnic, national, gendered and religious lines.

In advancing this concept, this study put into dialogue a focus on power, affect and the everyday with Avtar Brah's (1996) notion of diaspora, which the author framed as a space where 'new forms of belonging and otherness are appropriated and contested' (Brah 1996, 243). By addressing the constitution of a diaspora space based on a 'homing desire' rather than on a 'desire for the homeland' (16), Brah's work has complicated forms of binary thinking around difference and belonging as constituted through the opposition of supposedly homogeneous and fixed categories such as here/there, past/present, them/us. This perspective has challenged a predominant ethnic lens in academic and policy debates on migration and 'race relations' in Britain, and beyond (Glick Schiller, Darieva, and Gruner-Domic 2011). Moreover, it highlighted the intersections of race, gender and class involved in the uneven negotiation of identity, solidarity, and belonging in everyday social domains. Brah's conceptualisation of diaspora space resonated in many ways with the participants' engagement with music-making, addressing as well long-discussed gaps in research on forced migration. In contrast with established policy and academic perspectives on the topic, ethnographic data and interview accounts discussed in this paper highlighted how ethnic and national origins represented one of many patterns of belonging amongst the group participants (see Malkki 1995; Fiddian-Qasmiyeh 2016). Practices of intersectional solidarity emerging in the group made visible both the gendered experiences of asylum and the mundane responses to a range of issues (e.g. suspension, destitution, isolation) that, although shared amongst the participants, often acquired specific gendered connotations. ${ }^{7}$ This was evident when Maryam opened her flat for other women's to cook and break the fast during Ramadan, and in Shukri's efforts to create and sustain a womenonly group. Furthermore, Brah's (1996) remarks on the multiplicity of diasporic experiences beyond specific ' genealogies of dispersion' (16) meaningfully related to the forms of displacement that most of the group's participants experienced not only in terms of exile from the homeland, but also as enforced dispersal, destitution, and uncertainty in Britain. In this sense, the group's public performances often became opportunities for 570 the participants to claim spaces of presence and belonging that exceeded ethnic/national, religious and linguistic affiliations.

At the same time, these practices seemed to extend Brah's reflections in ways that were not fully explored in her work. Brah's conceptualisation mostly drew on the political mobilisations of British Black Feminist groups. The idea of a diaspora space mainly addressed domains such as workplace struggles, youth unemployment, education, and the politics of representation of people, and particularly women, of colour $(1996,240)$. Although Brah's concept was fundamental to discuss several of the practices and relationalities emerging from the group, the data nevertheless highlighted how the participants often expressed and addressed realities of suspension, destitution, marginality as and through embodied and affective states. These registers of experience thus required a conceptual framework that could grasp their significance as part of the affective politics of asylum described earlier in this study. The concept of affective practices of diasporic belonging thus connects Brah's focus on the 'diaspora spaces' emerging from everyday social domains with an attention to the affective and material registers through which uncertainty, marginality and destitution are inscribed and negotiated in forced migrants' lives. 
Some considerations are important to make at this point in relation to the main aims of this study. Firstly, the affective intensities and practices discussed here only in part represented the planned and expected outcome of the participants' involvement in the group. The capacity to shape the affective intensities and practices emerging from the weekly sessions was never confined to music-making alone, as a pre-determined, unproblematic 'fix' to the participants' marginality and exclusion. Rather, the affective registers and negotiations considered in this study emerged in association with the discursive and material elements that composed the group: the policy apparatus regulating the lives of many of the participants, the self-managed format, the space, instruments and support (e.g. transportation, childcare) available (or not) for the sessions, the sounds that the instruments enabled, and the diverse trajectories, meanings, and longings that each participant carried to the group. The capacity of music-making to produce certain affective intensities and relationalities cannot be understood outside of these collective entanglements. The responses to these entanglements (in terms of intensities, relationalities and practices) emerged in conjunction with each other in ways that could not be completely foreseen or planned by anyone involved (see also Darling 2014). The productivity of the participants' practices seemed thus to stem from the indeterminacy of the outcomes emerging from the 'heterogeneous collective' (Hughes and Forman 2017) of bodies, instruments and sounds constituting the music group. These mundane encounters facilitated the emergence of contingent though significant affective registers that were traced as part of personal trajectories, represented in interviews, poems, field-notes, and mobilised further through other practices of diasporic belonging like those mentioned earlier in this section. The practices emerging in and from the music-group-entanglement thus constituted what Dawney (2013) called sites of intensity: not just discursive or symbolic, but lived and felt domains where the 'gradual wounding' (Mayblin, Wake, and Kazemi 2020) produced by the asylum regime was both made manifest and negotiated. The discussion of affective practices of diasporic belonging thus contributed to offer novel considerations on forced migrants experiences and negotiation of asylum regimes. It did so through a focus which allowed to engage with the very materials, affects and encounters on which an exclusionary politics of asylum is based. Concurrently, this focus also highlighted the registers and relationalities emerging from mundane encounters (such as the musicmaking-entanglement) that temporarily, but productively interrupted the affective politics of asylum. Not aiming to minimise the harms inflicted upon forced migrants in the spaces and processes of the asylum system, this discussion nevertheless highlighted the relevance of recognising (in)visible, contingent, but productive domains of negotiation of the asylum regime (see also Darling 2014). The contributions and implications that this perspective can provide to wider scholarly analysis on forced migration and sanctuary will be outlined in more details in the following, final section.

\section{Conclusions}

Drawing on in-depth ethnographic participation in weekly music sessions co-created by a group of forced migrants in Bristol, this paper addressed the affective politics of asylum at play within mundane encounters in refugees' everyday lives. A first contribution advanced by this paper consisted in exploring the relevance of music-making in contexts of (forced) migration beside the registers of the symbolic, the textual and the discursive, and beyond 
understandings of music as a cultural signifier of ethnic/national forms of identification amongst displaced populations.

By expanding Brah's concept of diaspora space (1996) through a focus on power, affect and the everyday, this study has explored the music-making-entanglement as an example of affective reconfigurations of sociality, belonging and solidarity amongst forced migrants from diverse origins. This theoretical lens has contributed to enrich existing analysis on the relevance of music amongst refugee populations, and academic and policy frameworks that have predominantly addressed refugees' everyday lives in resettlement through national/ethnic lenses. Through the concept of affective practices of diasporic belonging, this study has highlighted an example of refugees' relationalities through which forms of belonging and solidarity emerge beside the canons of host/refugee relationships and established forms of 'hospitality'.

Relatedly, a second contribution advanced by this study relates to current discussions on forced migrants' everyday experiences, socialities, and negotiations of asylum regimes. The findings of this study can thus be relevant for migration researchers, as well as advocates and community organisers, in drawing further attention to 'mundane' spaces of sociality that can exceed (un)problematic accounts of 'hospitality' and 'generosity' towards refugees. The discussion highlighted the ethical and political relations at stake in spaces and practices of sociality and belonging where forced migrants are not just 'grateful recipients of care' (Darling 2011b, 414), and can disrupt apparently unescapable subject positions such as 'refugee', 'service user' and ultimately 'guest' in contexts of resettlement.

Relatedly, the study's focus on the affective and embodied registers of lives lived in the asylum system does not aim to 'distract' scholars and advocates from the importance of staking political claims (with, or on behalf of refugees) within forced migration debates and campaigns (e.g. on asylum seekers' right to work, housing, against detention and deportations). Rather, an attention to the affective politics of asylum can bridge these forms of solidarity and praxis. It can do so by underlining that efforts to challenge the available lexicon, moral assumptions and practices surrounding forced migration can benefit from 'a politics that is attentive to more than simply the discursive channels 660 through which abjection works' (Darling 2014, 496). The engagement with the affective registers and practices emerging from the participants' weekly music groups thus offered insights that opened and started to address a series of questions that can inform further analysis on the issues considered in this paper: How can issues of forced migration, solidarity and sanctuary can be understood, practiced and explored differently through a recognition and engagement with the affective politics of asylum? What tensions, possibilities and negotiations such focus can attune to, and make visible? How a focus on 'actually existing' affective practices of diasporic belonging can contribute to socially and politically generative acts, spaces and encounters beyond narratives of 'hospitality' and 'generosity'?

In calling researchers, community organisers and advocates alike to consider and explore these and further related questions, this paper contributed to a perspective that extends the domains of contention and negotiation of the politics of asylum to the (in)visible registers, practices and domains where the effects of such politics are lived, felt, materialised, and negotiated. 


\section{Notes}

1. As described by Darling (2014), Canning (2019), Mayblin et al. (2020).

2. Asylum-seekers live with a $£ 37.67$ weekly allowance while waiting for their asylum response.

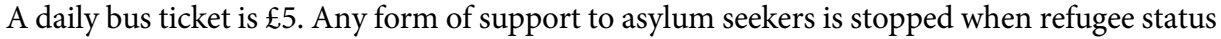
is recognised as they become eligible for welfare support. It is common for refugees to live in destitution and homelessness while waiting for the receipt of council accommodation and welfare support. According to Bristol council figures, around 140 refugees live in destitution in the city (Bristol City Council 2017). Several of the group participants were destitute/homeless at some point while participating to the groups.

3. The community venue that hosted the group, Hamilton House, was evicted between March and December 2018 to be transformed in residential apartments.

4. The music-group had resumed its weekly sessions in Bristol from October 2019 with similar support from Borderlands and Refugee Week Festival charities;

5. Children between few months and eight years old also occasionally attended the groups, mainly with their mothers.

6. Sudan, China, Cambodia, Pakistan, Iraq, Iran, Democratic Republic of Congo, Ethiopia, Taiwan, Mali, Vietnam, India, Uganda, Great Britain, Italy, Peru.

7. The harmful gendered implications of asylum policies have been addressed by Mountz (2011); Schmoll (2014); Baillott and Connelly (2018); Canning (2019).

\section{Acknowledgements}

Earlier versions of this paper were presented at the Leisure Studies Association 2018 and British Sociological Association 2019 annual conferences, and to seminar audiences at Bournemouth University, and University of Brighton. My thanks to the organisers and audiences at each of these forums for their constructive engagement with my work. Thanks to the anonymous reviewers for their insightful comments. The paper has also benefitted at different stages from the insights of Ian Jones, Nichola Khan, and Aarti Ratna, my thanks to you all. Finally, a heartfelt thanks to all the men and women who animated and (still animate) the music group for their time, care and patience during this research.

\section{Disclosure statement}

Q9 No potential conflict of interest was reported by the author(s).

\section{Funding}

Q3 This work was supported by Bournemouth University and by the Leisure Studies Association 'Research and Enterprise Development' Fund.

\section{ORCID}

Nicola De Martini Ugolotti (i) http://orcid.org/0000-0001-5149-7617

\section{Q10 References}

Ahmed, S. 2004a. The Cultural Politics of Emotion. Edinburgh: Edinburgh University Press.

Ahmed, S. 2004b. "Collective Feelings Or, The Impressions Left by Others." Theory, Culture \& Q11 Society 21 (2): 25-42.

Anderson, B. 2016. Encountering Affect: Capacities, Apparatuses, Conditions. London: Routledge. 
Bailey, J., and M. Collier. 2006. "Introduction: Music and Migration." Journal of Ethnic and Migration Studies 32 (2): 167-182.

Baillott, H., and E. Connelly. 2018. Women Seeking Asylum: Safe from Violence in the UK? London: Refugee Council.

Beneduce, R. 2015. "The Moral Economy of Lying: Subject-craft, Narrative Capital, and Uncertainty in the Politics of Asylum.” Medical Anthropology 34 (6): 551-571.

Brah, A. 1996. Cartographies of Diaspora: Contesting Identities. London: Routledge.

Bristol City Council, 2017. Bristol: A City of Sanctuary Welcoming Asylum Seekers and Refugees Strategy. https://democracy.bristol.gov.uk/documents/s16871/01\%20Welcoming\%20Asylum\% 20Seekers\%20and\%20Refugees\%20Strategy\%20V5.pdf

Canning, V. 2019. "Degradation by Design: Women and Asylum in Northern Europe." Race and Class 61 (1): 46-63.

Coplan, D. B. 2006. “'I've Worked Longer Than I've Lived': Lesotho Migrants' Songs as Maps of Experience." Journal of Ethnic and Migration Studies 32 (2): 223-241.

Darling, J. 2011a. "Domopolitics, Governmentality and the Regulation of Asylum Accommodation.” Political Geography 30: 263-271.

Darling, J. 2011b. "Giving Space: Care, Generosity and Belonging in a UK Asylum Drop-in Centre." Geoforum; Journal of Physical, Human, and Regional Geosciences 42: 408-417.

Darling, J. 2017. "Forced Migration and the City: Irregularity, Informality, and the Politics of Presence.” Progress in Human Geography 41 (2): 178-198.

Darling, J. 2014. "Another Letter From the Home Office: Reading the Material Politics of Asylum." Environment and Planning D: Society and Space 32: 484-500.

Darling, J. 2013. "Moral Urbanism, Asylum, and the Politics of Critique." Environment and Planning A: Economy and Space 45: 1785-1801.

Dawney, L. 2013. "The Interruption: Investigating Subjectivation and Affect." Environment and Planning D: Society and Space 31: 628-644.

Fassin, D., and E. D'Halluin. 2005. “The Truth From the Body: Medical Certificates as Ultimate Evidence for Asylum Seekers." American Anthropologist 107 (4): 597-608.

Fiddian-Qasmiyeh, E. 2016. "Refugee-Refugee Relations in Contexts of Overlapping Displacement." International Vournal of Urban and Regional Research. http://www.ijurr.org/ spotlight-on-overview/spotlight-urban-refugee-crisis/refugee-refugee-relations-contextsoverlapping-displacement/

Glick Schiller, N., T. Darieva, and S. Gruner-Domic. 2011. "Defining Cosmopolitan Sociability in a Transnational Age. An Introduction.” Ethnic and Racial Studies 34 (3): 399-418.

Hughes, S. M., and P. Forman. 2017. "A Material Politics of Citizenship: The Potential of Circulating Materials From UK Immigration Removal Centres.” Citizenship Studies 21 (6): 675-692.

Hynes, P. 2011. The Dispersal and Social Exclusion of Asylum Seekers: Between Liminality and Belonging. Bristol: University of Bristol Policy Press.

Kasinitz, P., and M. Martiniello. 2019. "Music, Migration and the City." Journal of Ethnic and Racial Studies 42 (6): 857-864.

Kaya, A. 2002. “Aesthetics of Diaspora: Contemporary Minstrels in Turkish Berlin.” Journal of Ethnic and Migration Studies 28 (1): 43-62.

Lewis, H. 2010. "Community Moments: Integration and Transnationalism at 'Refugee' Parties and Events.” Journal of Refugee Studies 23 (4): 571-588.

Lewis, H. 2015. "Music, Dancing and Clothing as Belonging and Freedom among People Seeking Asylum in the UK." Leisure Studies 34 (1): 42-58.

Lidskog, R. 2016. "The Role of Music in Ethnic Identity Formation in Diaspora: a Research Review." International Social Science Journal 66 (219-220): 23-38.

Longhurst, R., L. Ho, and L. Johnston. 2008. “Using 'The Body' as an 'Instrument of Research': Kimch'i and Pavlova." Area 40 (2): 208-217.

Malkki, L. 1995. "Refugees and Exile: From 'Refugee Studies' to the National Order of Things." Annual Review of Anthropology 24: 495-523. 
Martiniello, M., and J. M. Lafleur. 2008. "Ethnic Minorities' Cultural and Artistic Practices as Forms of Political Expression: A Review of the Literature and a Theoretical Discussion on Music." Journal of Ethnic and Migration Studies 34 (8): 1191-1215.

Mayblin, L. 2017. Asylum After Empire: Colonial Legacies in the Politics of Asylum Seeking. London: Rowman and Littleman.

Mayblin, L., and P. James. 2019. “Asylum and Refugee Support in the UK: Civil Society Filling the Gaps?” Journal of Ethnic and Migration Studies 45 (3): 375-394.

Mayblin, L., M. Wake, and M. Kazemi. 2020. "Necropolitics and the Slow Violence of the Everyday: Asylum Seeker Welfare in the Postcolonial Present." Sociology 54 (1): 107-123.

Mbembe, A. 2003. "Necropolitics." Public Culture 15 (1): 11-40.

Mountz, A. 2011. "Where Asylum-Seekers Wait: Feminist Counter-Topographies of Sites Between States." Gender, Place \& Culture 18 (3): 381-399.

Navaro-Yashin, Y. 2009. "Affective Spaces, Melancholic Objects: Ruination and the Production of Anthropological Knowledge." Journal of the Royal Anthropological Institute 15 (1): 1-18.

Pelham, J., and D. McGee. 2018. "Politics at Play: Locating Human Rights, Refugees and Grassroots Humanitarianism in the Calais Jungle." Leisure Studies 37 (1): 22-35.

Probyn, E. 2000. Carnal Appetites: Food sex Identities. London: Routledge.

Probyn, E. 2005. Blush: Faces of Shame. Minneapolis: University of Minnesota Press.

Rozakou, K. 2016. "Socialities of Solidarity: Revisiting the Gift Taboo in Times of Crisis." Social Anthropology 24 (2): 185-199.

Sandri, E. 2018. "Volunteer Humanitarianism': Volunteers and Humanitarian aid in the Jungle Refugee Camp of Calais." Journal of Ethnic and Migration Studies 44 (1): 65-80.

Schmoll, C. 2014. "Gendered Spatialities of Power in 'borderland' Europe: an Approach Through Mobile and Immobilised Bodies." International Journal of Migration and Border Studies 1 (2): 173-189.

Squire, V. 2009. The Exclusionary Politics of Asylum. Basingstoke: Palgrave Macmillan.

Squire, V. 2011. "From Community Cohesion to Mobile Solidarities: The City of Sanctuary Network and the Strangers Into Citizens Campaign." Political Studies 59: 290-307.

Van Aken, M. 2006. "Dancing Belonging: Contesting Dakbeh in the Jordan Valley, Jordan." Journal of Ethnic and Migration Studies 32 (2): 203-222.

Waitt, G., E. Ryan, and C. Farbotko. 2014. "A Visceral Politics of Sound.” Antipode 46 (1): 283-300.

Wilcock, C. A. 2019. "Hostile Immigration Policy and the Limits of Sanctuary as Resistance: Counter-Conduct as Constructive Critique." Social Inclusion 7 (4): 141-151.

Zaman, T., 2019. "Neighbourliness, Conviviality, and the Sacred in Athens' Refugee Squats." Transactions of the Institute of British Geographers. doi:10.1111/tran.12360 